\title{
Processos metafóricos de emolduração no cinema e nas mídias digitais
}

Mariana Tavernari'

1. Doutoranda no Programa de Pos-Graduação em Meios e Processos Audiovisuais da Escola de Comunicações e Artes da Universidade de São Paulo. Mestre em Ciências da Comunicação pela Universidade de São Paulo. Pesquisadora e bolsista (FUSP) do NAP Escola do Futuro. Membro do grupo de pesquisa "MidiAto - Crupo de Estudos de Linguagem: Práticas Midiáticas", da USP. E-mail: mariana.tavernari@gmail.com 


\section{Resumo}

O artigo analisa os conceitos de moldura e janela para evidenciar os processos metafóricos de emolduração no cinema e nas mídias digitais e os mecanismos que regulam a produção e o consumo imagético na contemporaneidade. Das particularidades perspectivistas dos aparatos tecnológicos que compõem o cinema e as mídias digitais às diferentes percepções da moldura em ambos, são abordadas as relações entre a moldura e a narrativa como uma função cultural, conectada às características do dispositivo, mas também fruto das novas formas de agenciamento e identificação, verificando-se as facetas empregadas no desejo de atingir e representar o real.

\section{Palavras-chave}

comunicação, audiovisual, imagem, moldura, mídias digitais

\section{Abstract}

The article analyzes the concepts of frame and window to illustrate the processes of metaphorical framing in film and digital media and the mechanisms that regulate the production and imagery consumption in contemporary times. From the particular perspectives of technological devices that constitutethe cinema and digital media tothe different perceptions of frame which they present, this article deals withthe relationship between the frame and the narrative as a cultural function connected to thecharacteristics of the device, but also the result of new forms of agency and identification, verifying the facetsemployed,aiming to reach and to represent reality.

\section{Keywords}

Communication, audiovisual, image, frame, digital media. 


\section{Introdução}

O artigo faz um percurso pelos conceitos de moldura e janela para evidenciar

temáticas

livres os processos metafóricos de emolduração no cinema e nas mídias digitais. Os mecanismos das molduras, que regulam a produção e o consumo das imagens, são abordados intrinsecamente às noções de centramento e descentramento e relacionados às formas de identificação e projeção com dispositivos técnicos.

Como se compõem as narrativas em rede? Quais estratégias narrativas permeiam a cibercultura? Com base nessa problemática, o artigo busca classificar as formas narrativas componentes da cibercultura, tratada aqui em sua dimensão epistemológica (MACEK, 2005), como contexto cultural do qual emergem práticas midiáticas e discursos decorrentes das tecnologias da informação e comunicação (TICs) - e do cinema. Essas formas narrativas podem ser comprovadas empiricamente por meio da observação dos fluxos narrativos em seus formatos convergentes e multimidiáticos, que ora simulam práticas imediadas, que se propõem como transparentes, ora mimetizam formas hipermediadas, muitas vezes interpretadas como opacas e "janeladas".

Trata-se de investigar como estão interligados esses processos de imediação e hipermediação (BOLTER; GRUSIN, 2000) no cinema e na rede, quais as facetas empregadas no desejo de atingir e representar o real - se miméticas (como no Second Life²), diegéticas (como nos blogues) ou um processo formado por ambas.

Das particularidades espaciais e temporais imanentes aos aparatos tecnológicos que compõem o cinema e as mídias digitais, às diferentes percepções da moldura em ambos, passamos a abordar as relações entre a moldura e a narrativa, como uma função estritamente cultural, conectada às características do dispositivo, mas também fruto das novas formas de agenciamento da contemporaneidade.

2. Ambiente virtual e tridimensional criado em 1999 que simula, em alguns aspectos, a vida real e social do ser humano. Na época, imaginava-se que suas propriedades de simulação se tornariam um modelo de rede social. 
Em rede, a narrativa deve ser constituída em termos teóricos não apenas como um ato textual de representação, mas também como um construto cognitivo, em função de sua multimodalidade. Essa dualidade problematiza também as formas narrativas tradicionais (BORDWELL, 1985), tanto como narração diegética (ou seja, o ato de contar a alguém que algo aconteceu), quanto como narração mimética (ato de mostração), este artigo propõe-se investigar quais as formas de combinação de ambas. O tempo da imagem nas mídias digitais, ao contrário do cinema, segue o fluxo do tempo do espectador, colocando a questão da dimensão temporal que se estabelece justamente na relação de simultaneidade entre o tempo do interator e o tempo da imagem, e problematizando também o gênero discursivo, exigindo um suposto saber do interator sobre a gênese da produção simbólica e seu modo de produção e circulação.

As molduras do ciberespaço e do cinema combinam formas narrativas miméticas e diegéticas, sinalizando um produto híbrido, composto por códigos fortes e fracos, no qual a fonte enunciativa é de difícil detecção: ora confundese com a imagem do personagem, ora com a do narrador, ora com a voz de ambos ou mesmo com a trilha sonora. No entanto, os processos metafóricos de emolduração ocorrem de maneiras distintas em ambos, devido às possibilidades interativas que as mídias digitais oferecem. Enunciador e enunciatário se confundem e materializam a fusão dos olhares que já anunciava o cinema poético.

\section{A representação perspectivista e a atividade do espectador}

O paradigma da janela de Alberti pressupunha uma objetividade científica nas operações de representação espacial, como se o espaço tridimensional pudesse apenas ser desenhado de determinada forma (retilínea e com pontos focais definidos) em uma superfície bidimensional. Esse fenômeno, denominado por Aumont (1993: 63) de "dupla realidade perceptiva da imagem", definia 
ano I número |

temáticas

livres

que a reprodução por meio da câmera, da lente ou mesmo do pincel somente seria concretizada se seguisse regras geométricas racionalmente calculadas, eliminando do jogo da reprodução a atividade humana. A partir desta forma de representar o mundo, de acordo com as regras culturais e históricas da perspectiva, surge como conceito o fenômeno perceptivo e cultural da ilusão, alicerce para muitas manifestações estéticas, como veremos adiante.

Se o cinema, com seus pontos de vista variáveis e compondo o espaço representado por meio da multiplicidade narrativa, já potencializava o poder agenciador do sujeito enunciador, a "interface janelada das redes digitais" (SERELLE, 2009) efetua diversos tipos de operações representativas, diferentes daquelas da pintura e do cinema. Aqui, tomamos "representação" no sentido de um fenômeno que permite ao “espectador 'ver por delegação' uma realidade aparente que lhe é oferecida sob a forma de um subtítulo" (AUMONT, 1993: 105).

A posição da câmera proposta pelo diretor do filme (por vezes colocada nos olhos do enunciador-personagem do cinema) perde seu caráter soberano para aquele que era apenas espectador. O ciberespaço evidencia aquilo que Bordwell (1985: 29) já defendia como a essência do cinema: não a passividade do espectador, mas seu papel ativo frente às operações lógicas esquemáticas entre a trama e a fábula. As mídias digitais devolvem ao espectador o papel extremamente ativo no fluxo imagético da contemporaneidade. Mais do que um simples ponto de vista - ou mesmo que um ponto de fala do sujeito narrador, que efetua operações de reprodução mimética do espaço visualizado -, as potencialidades interativas do ciberespaço dão novamente ao espectador o poder de atuar sobre a imagem ou sobre o objeto da representação. 


\subsection{Estabilização mimética e fissuras poéticas no cinema}

Tido como impessoal, o cenário criado a partir da lente deveria corresponder a uma ideia de reprodução automática, como se o filtro da câmera inexistisse. O olho tem estatuto ambíguo nessa relação: ora corresponde à incorporação mais comum dessa barreira física, ora é a materialização do objeto viabilizador e visualizador da imagem representada, objeto cultural e histórico (AUMONT, 1993: 73). Dessa relação sistematizada e regrada entre o sujeito da representação e o objeto representado nasce a ideia do olho totalizador, que tudo pode na sua função de ancorar espacialmente o mundo.

Essa estabilização mimética renascentista suporta muitas das concepções utilizadas em diversas manifestações artísticas atualmente, mesmo em videogames, especialmente os jogos em primeira pessoa, como o conhecido Black Ops, exemplificado na Figura 1:

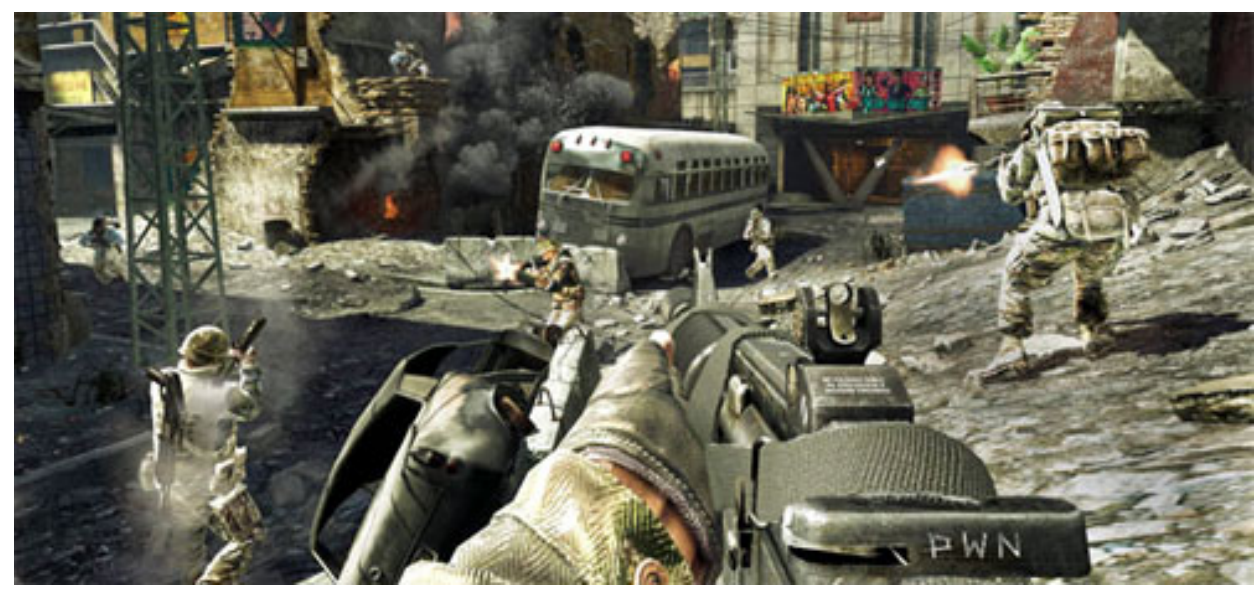

Figura 1: Jogo em primeira pessoa Black Ops.

No entanto, diferentemente do cinema, as operações de agenciamento efetuadas com esses novos dispositivos configuram outras formas de conceber o sujeito no mundo, mais (inter)ativas.

Esse estatuto da câmera no cinema (pelo menos nos casos em que ela persegue o narrador ou é a incorporação do seu olhar) contribui para a ideia de onipotência da perspectiva e de onipresença do enunciador. A essa transcendência 
ano I número

temáticas

livres corresponde também um ideal de continuidade narrativa que percorre a história do cinema clássico, de modo a dividir os cem anos de produção cinematográfica em dois grandes paradigmas representativos: o primeiro, aquele da continuidade espaçotemporal dissimulada pelas narrativas (melodramáticas, principalmente) que buscam o realismo como forma mais genuína de representação; o segundo, aquele que rompe justamente com essa ordem, dispersando a centralidade narrativa que se fundia com a concepção de paralelismo entre um sujeito criador e outro, espectador, deslocando pontos de vista.

Do cinema dito poético, em que os planos da expressão e do conteúdo muitas vezes se contradizem, evidenciando as idiossincrasias de cada um deles, emanam processos poéticos que antecipam o papel ativo do espectador nas mídias digitais e o hipertexto como obra aberta: dos personagem de Bill Viola, em Observance (2002), que olham para fora da tela aos descentramentos centrífugos, é instaurada uma nova forma de relação entre sujeito o objeto da representação, entre enunciador e enunciatário: da tela dentro da tela, o personagem olha para fora da janela, como se conhecesse a existência do espectador (conforme Figura 2).

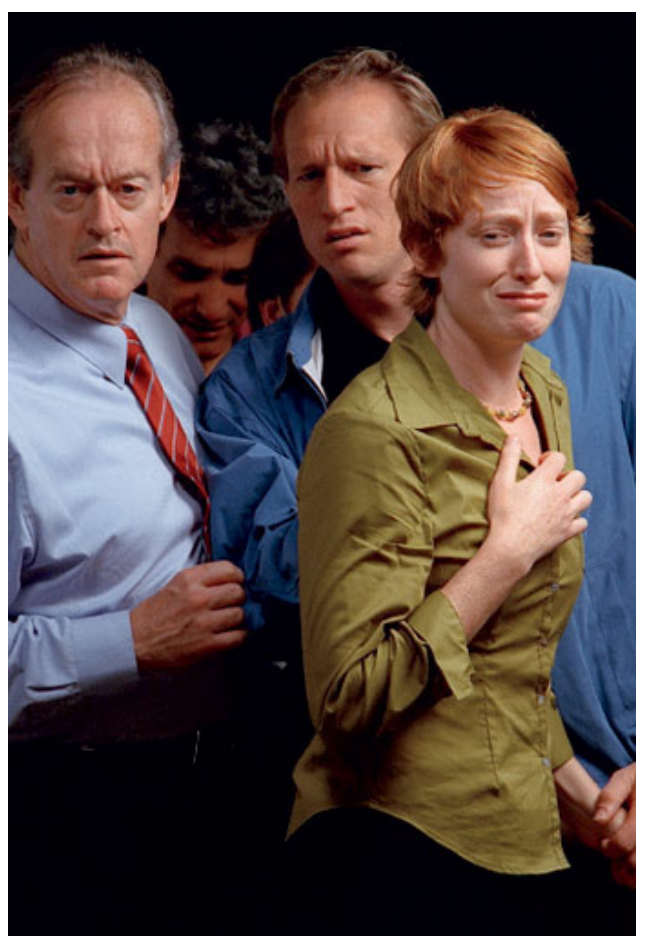

Figura 2: Cena do filme Observance (Bill Viola, 2002). 
Na comunhão dos olhares emoldurados emergem princípios metafóricos da ordem da enunciação enunciada. O cinema prenuncia a atividade do espectador nas mídias digitais, mesmo apoiadas em interfaces janeladas perspectivistas.

\subsection{Janela albertiniana e os dispositivos digitais}

Como uma câmera nos lugar dos olhos do observador, a noção de perspectiva no ciberespaço potencializa a função representativa da perspectiva renascentista albertiniana, ou seja, a interface dos dispositivos (especialmente a janela do sistema operacional mais utilizado, o Windows, da empresa Microsoft) ainda mimetiza as operações apoiadas na perspectiva, conforme pode ser observado na Figura 3.

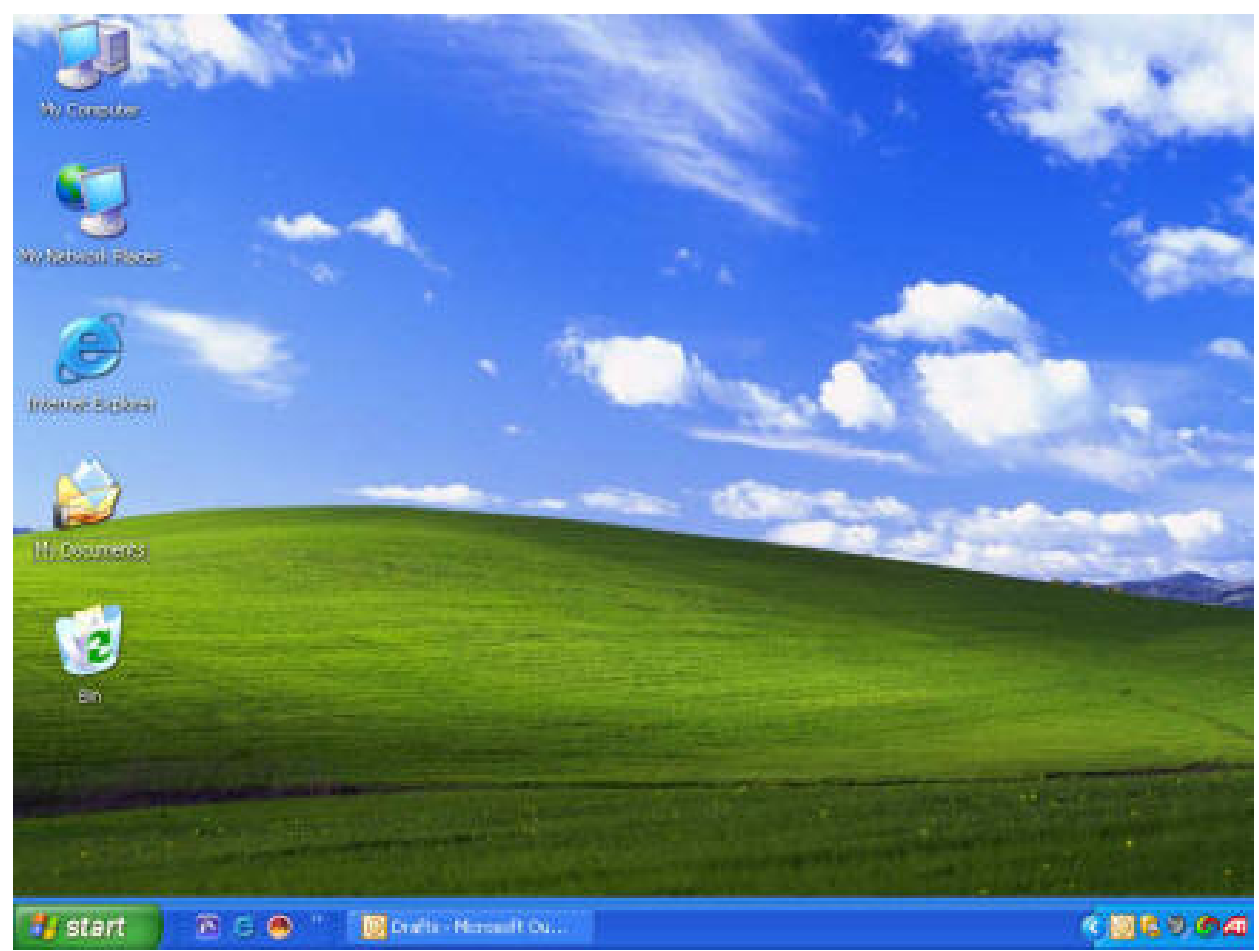

Figura 3: Área de trabalho do Sistema Operacional Windows, da Microsoft.

O formato de apresentação dos navegadores e aplicativos dos principais sistemas operacionais reproduz a metáfora da janela centrífuga de Alberti. A 
ano I número |

temáticas

livres

consciência de perspectiva é essencialmente espacial e está baseada em uma separação espacial entre o sujeito da representação e o objeto representado, de modo a tornar as distâncias entre ambos mais curtas e oferecer uma relação objetiva e focada dessa mirada. Essa visão transcendental tem como centro o sujeito, instância fundadora e causal do discurso idealista (MACHADO, 2007: 41).

Ainda que os novos dispositivos de mídias digitais estejam apoiados no perspectivismo, podem ser observados pontos díspares dessa visão: o objeto representado perde sua referência direta com o mundo dito real, ou seja, quebra-se o pacto da referencialidade em que estão apoiados a televisão, o cinema e a fotografia. Os objetos que o sujeito experimenta nas mídias digitais não são apenas representações imagéticas, mas objetos informacionais, bits e bytes que se atualizam de acordo com a interação. A imagem digital que se atualiza na interface hipertextual, seja ela composta por ícones ou textos verbais, é uma função matemática.

A referencialidade que apoia e ancora a fotografia jornalística, por exemplo, na origem do espaço captado pela lente e representado bidimensionalmente no papel é escancarada. A arbitrariedade do signo desvela-se diante dos defensores vorazes da imagem representada como cópia fiel do mundo real.

Olhos perspectivistas em uma concepção moderna distanciam o sujeito da representação, imerso no mundo real dos objetos representados. A presença da mediação, por meio de dispositivos técnicos, promove um distanciamento entre sujeito e objeto que favorece as crenças no estatuto "verdadeiro" da imagem mediada. A mediação, ao mesmo tempo em que promove essa pregnância na "realidade real", acentua o efeito de distanciamento.

Ainda no cinema clássico, fundamentado em operações de identificação e máquina integrada de produção de sentido, essa mediação ainda conta com um fio de Ariadne entre o significado e o significante. Com as mídias digitais, esse 
fio se rompe definitivamente. Funda-se uma nova ordem epistêmica, baseada justamente nessa desconexão revelada por uma nova relação de agenciamento. Cria-se uma articulação de planos que difere do jogo campo-contracampo do cinema clássico. Os planos nos meios digitais perdem sua referencialidade, sobrepõem-se, criam um jogo de espelhos em que se rompe o sistema da sutura que suporta o cinema clássico.

\section{Processos de emolduração: espaço e tempo representados}

A maior parte dos dispositivos técnicos de reprodução imagética na contemporaneidade compõe uma espécie de metáfora da moldura ou da janela. Se de toda moldura emana um princípio metafórico, as molduras das interfaces digitais criam uma metáfora espacial. Já pela nomenclatura, é possível observar que o ciberespaço segue uma ordenação sincrônica, fundamentada nas categorias de espaço em detrimento das de tempo.

Jameson já enfatizava essa particularidade das formas de subjetivação na contemporaneidade. Uma orientação essencialmente visual, baseada em um paradigma relacional entre sujeito e objeto construído com base na função do olhar, a dimensão humana da visão, que define sua intencionalidade e finalidade (AUMONT, 1993: 59). O eu que olha é o centro a partir do qual se vê o mundo. O espaço é conquistado, colonizado pela compactação do tempo.

\footnotetext{
O ciberespaço apresenta uma nova visão global e uma sensibilidade fundamentalmente diferente, onde a imagem cartográfica do globo não precisa mais representar ou substituir o "mundo real", pois, no ciberespaço, a imagem tornou-se "o mundo". Dentro de um mundo hiperperspectivo, o mapa é o território, e, seguindo o argumento de Baudrillard (1983), até mesmo precede ou substitui o mundo real. (PURSER, 1999) 3
}

3. "Cyberspace introduces a new global vision and fundamentally different sensibility, where the cartographic image of the globe no longer needs to stand in for or represent the 'real world' because in cyberspace the image has become 'the world'. Within a hyperperspectival world, the map is the territory, and, following Baudrillard's (1983) argument, even precedes or supersedes the actual world." (Tradução da autora.) 
ano I número |

temáticas

livres

A dimensão espacial do dispositivo, que promove a relação entre a imagem e o espectador - nas palavras de Aumont - como meio técnico, modo de circulação das imagens e suporte, oferece ao espectador um espaço plástico em cuja superfície emerge a imagem. Mais especificamente em relação ao suporte, esse espaço plástico é chamado de moldura, que pode ou não ser aparente, ao contrário do sentido denotativo da palavra.

As formas de representação da imagem passam pela definição da centralização ou descentralização do objeto representado. Na moldura operam campos de forças variados, em que o centro absoluto é ocupado pelo espectador. No caso das mídias digitais, a presença da moldura-objeto é constante, ou seja, aparente, e circunda a imagem, recriando-a. A forma de produção e consumo das imagens na contemporaneidade é regulada por um dispositivo que não congela a imagem, mas permite o desenquadramento de acordo com a ação do espectador.

Esses movimentos na direção da máxima hipermediação podem ser observados de forma ainda mais acentuada em aplicativos de redes sociais recentes, caso do Pinterest, rede social na internet de compartilhamento de imagens que funciona como um grande mural, como mostra a imagem abaixo:



Figura 4: Mural da rede social Pinterest. 


\subsection{Molduras cinematográficas}

Além de suas funções visuais (perceptivas), econômicas e simbólicas, a moldura funciona como designador de um mundo à parte, ou seja, uma "aber tura que dá acesso a um mundo imaginário, à diegese figurada pela imagem" (AUMONT, 1993: 147). A moldura-limite é o que interrompe a imagem e the define o domínio ao separá-la do que não é a imagem, é o que institui um fora de moldura (que não deve ser confundido com fora de campo (AUMONT, 1993: 147). Esse é um dos princípios metafóricos no qual está apoiado o cinema. Nas mídias digitais, a coexistência da moldura-objeto com seu valor econômico e da moldura-janela com seu valor retórico cria efeitos metafóricos variados.

No entanto, se já a moldura limite define os modos de enquadramento e desenquadramento no cinema, muitas vezes a moldura-janela acentua seu papel retórico, remetendo a figuras cristalizadas e recorrentes que fazem parte do mundo diegético. É o caso de Arca russa, do diretor Alexander Sukurov. Muitos são os filmes que empregam esse mecanismo retórico anagramático, colocando em jogo molduras-limite e molduras-janela simultaneamente, instaurando efeitos de sentido poéticos, criando metáforas do mundo interior das personagens por meio de figuras arquetípicas, como a colmeia no lugar da porta em El espíritu de la colmena, do diretor Victor Erice.

No cinema, a clivagem entre as formas centradas e descentradas institui a divisão entre o cinema clássico, pautado pelo ideal da testemunha invisível dos acontecimentos da diegese, e o cinema moderno, opaco, descentrado, chamado por Aumont de olhar variável. O desenquadramento no cinema moderno suscita um vazio no centro da imagem, remarca o quadro como borda da imagem e se resolve na sequencialidade. 


\subsection{Janelas e mídias digitais}

A interface das mídias digitais opera como uma ponte entre o artefato

temáticas

livres tecnológico e o ambiente externo, de onde partem as operações de navegação. Esse aspecto de mediação também aparece na definição de Johnson (2001: 14): 4 "de forma simples, a palavra [interface] remete ao software que dá forma à interação entre o usuário e o computador".

A interação homem-máquina sofre alterações desde o nascimento do primeiro computador. O primeiro paradigma de interface está apoiado na ideia de linha de comandos em uma tela, que poderiam ser alterados com a interação humana. No entanto, esse paradigma ainda dependia da expertise dos usuários, dependia de conhecimentos de complexas linguagens de prog ramação. Com o surgimento do mouse em 1968 e das janelas dos navegadores, predomina o paradigma da área de trabalho, em que a interface simula ações do mundo real, por meio de uma representação icônica de objetos do cotidiano: arquivos, pastas, mesas etc., segundo o conceito "what you see is what you get".

A metáfora de área de trabalho dá continuidade à estética da simulação, ou seja, à ideia de que a mediação entre usuário e computador opera um efeito de opacidade, de distanciamento entre ambas as instâncias da representação. Essa camada criada entre ambos torna mais intermediada essa relação, ao contrário do que se poderia imaginar (TURKLE, 1997: 50).

Com o desenvolvimento de interfaces voltadas especialmente para novas formas de interação com o usuário, por meio de funcionalidades próximas de experiências estéticas, o paradigma da interface da área de trabalho vai sendo substituído por outro baseado no toque, além do contato com uma superfície intermediária. Computadores com telas sensíveis ao toque e ao multitoque

4. "In its simplest sense, the word [interface] refers to software that shapes the interaction between user and computer." (Tradução da autora.) 
invadem o mercado. Esses dispositivos são normalmente compostos por um sensor que detecta uma alteração no ambiente (proximidade de outro objeto, pressão, movimento, luz) e, a partir disso, emite comandos específicos de acordo com o movimento do dispositivo.

O iPad, tablet da Apple Inc., ${ }^{5}$ um dos aparelhos mais vendidos em todo o mundo, é objeto símbolo da cultura das imagens. Apesar do desenvolvimento tecnológico, continuamos presos às "janelas", aos ecrãs, às metáforas. Esse dispositivo possui uma tela de dez polegadas e é voltado para o entretenimento móvel, no qual um dos aplicativos mais utilizados é o Flipboard, que emprega o mesmo formato emoldurado do Pinterest e permite a leitura de conteúdos provenientes de redes sociais por meio da navegação com os dedos (Figura 5).

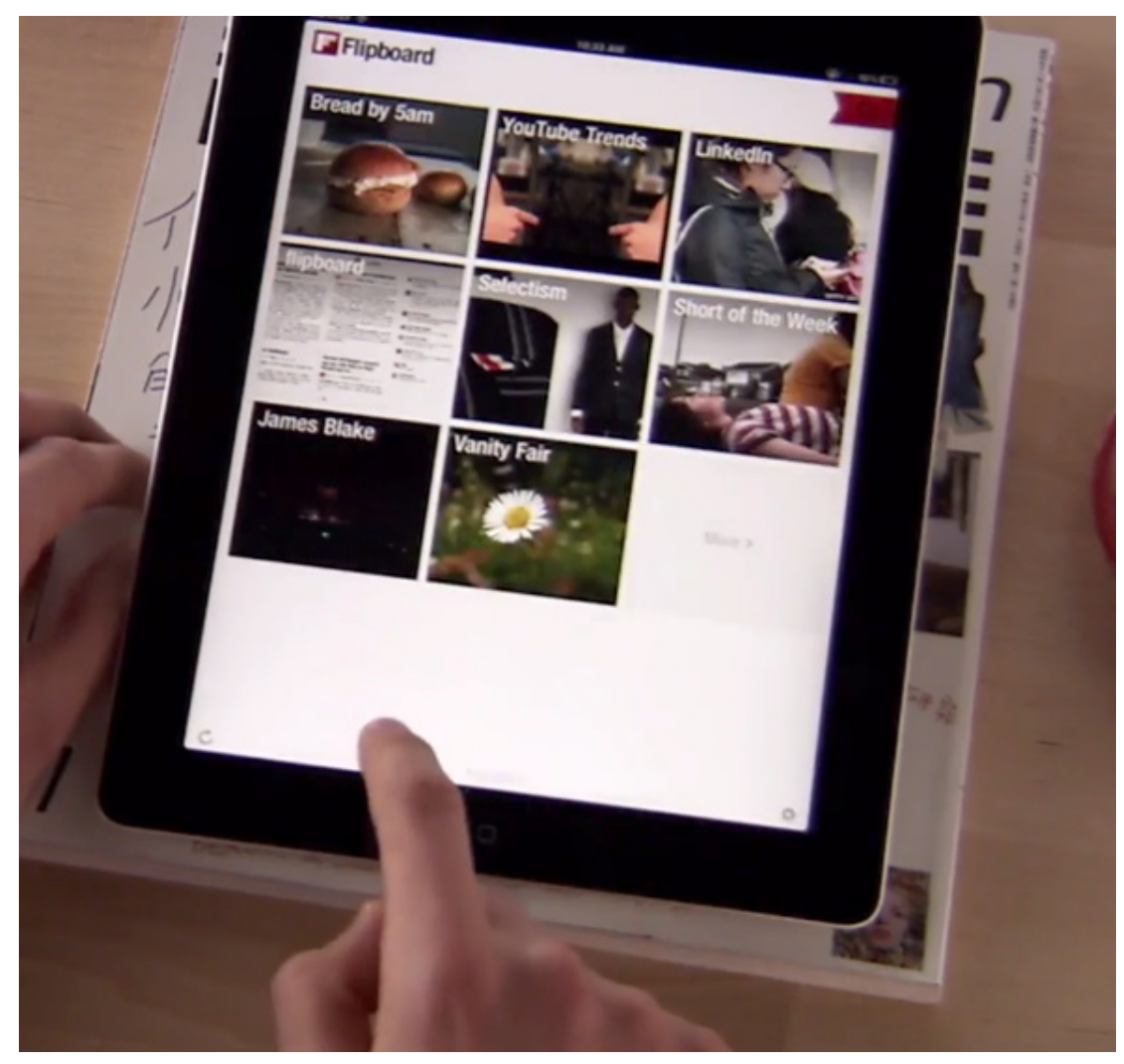

Figura 5: iPad com aplicativo Flipboard.

5. Empresa multinacional estadunidense de produtos eletroeletrônicos de grande sucesso, como o telefone iPhone e o tocador de músicas iPod. 
ano I número 1

temáticas

livres

Todas as aplicações integradas foram concebidas para comportar a interação a partir do toque, respondendo a ações variadas com os dedos. O aparelho tem funcionalidades semelhantes às de um computador com tela de alta resolução e sem teclado - que surge de acordo com a necessidade, na própria tela. Abandonase o mouse e do teclado, mas ainda a metáfora da moldura está presente.

Há cerca de cinco anos, o objeto que simbolizava o caráter espacial do ciberespaço era o computador de mesa, imóvel. À frente dele, postava-se o espectador, interagindo com a máquina e impossibilitado de deslocarse livremente no ambiente físico. Um suporte móvel, que acompanha o movimento do espectador e, mais que isso, pode responder a algumas ações interativas efetuadas por ele - caso da ferramenta giroscópio - modifica a relação humana com o espaço e o tempo. O fenômeno mobile, encabeçado pelos celulares com câmeras e computadores de mão, propõe um novo tipo de relação entre espectador e imagem.

\section{Narrativas emolduradas}

O cinema, a arte do espaço e do tempo emoldurados, configura-se como uma manifestação estética fundada no acontecimento e na causalidade, fixando o tempo em determinado espaço por meio de operações actanciais realizadas por narradores e personagens. Instaurada a cena, os acontecimentos e causalidades engendram um "conjunto organizado de significantes cujos significados constituem uma estória" (AUMONT, 1993: 244): a narrativa. Essa narrativa se dá, de acordo com as teorias miméticas da narração, por meio da perspectiva, implicando o espectador como testemunha invisível (BORDWELL, 1995: 09).

A narrativa é a representação de uma estória (acontecimentos ou uma série de acontecimentos) - chamada também de fábula -, uma sequência cronológica de acontecimentos envolvendo entidades. Além da estória, “o outro componente da narrativa é a trama, a ordem em que os eventos acontecem na narrativa" 
(ABBOTT, 2008: 33). A estória (ou fábula) nunca está materialmente presente no filme e pode apenas ser pressuposta pelo espectador por meio de esquemas cognitivos. A trama, por sua vez, é a representação da fábula.

O romance, o cinema e o teatro pressionavam esses limites da narrativa linear. O contrato fiduciário de leitura com o espectador já pressupunha uma audiência ativa, capaz de operar interpretações e preencher lacunas de sentido. Se, como expressão artística verbal, a literatura problematizava a delegação de vozes no interior da narrativa, nas narrativas audiovisuais a questão da enunciação como instância fundadora do discurso complexifica-se.

\subsection{Tramas cinematográficas}

Como filme estritamente metafórico, a relação entre estória e discurso em El espíritu de la colmena permite leituras ambíguas e interpretações simbólicas de seus personagens, plasmados sempre pelas molduras, físicas ou não. Esse aspecto poético está diretamente relacionado a um tipo bastante específico de narrativa, a chamada "narrativa embedada", bastante presente no cinema. A polissemia própria da função poética, nesse caso, emerge principalmente da figura arquetípica da colmeia, presente em diversas instâncias do filme, conforme pode ser observado na Figura 6.

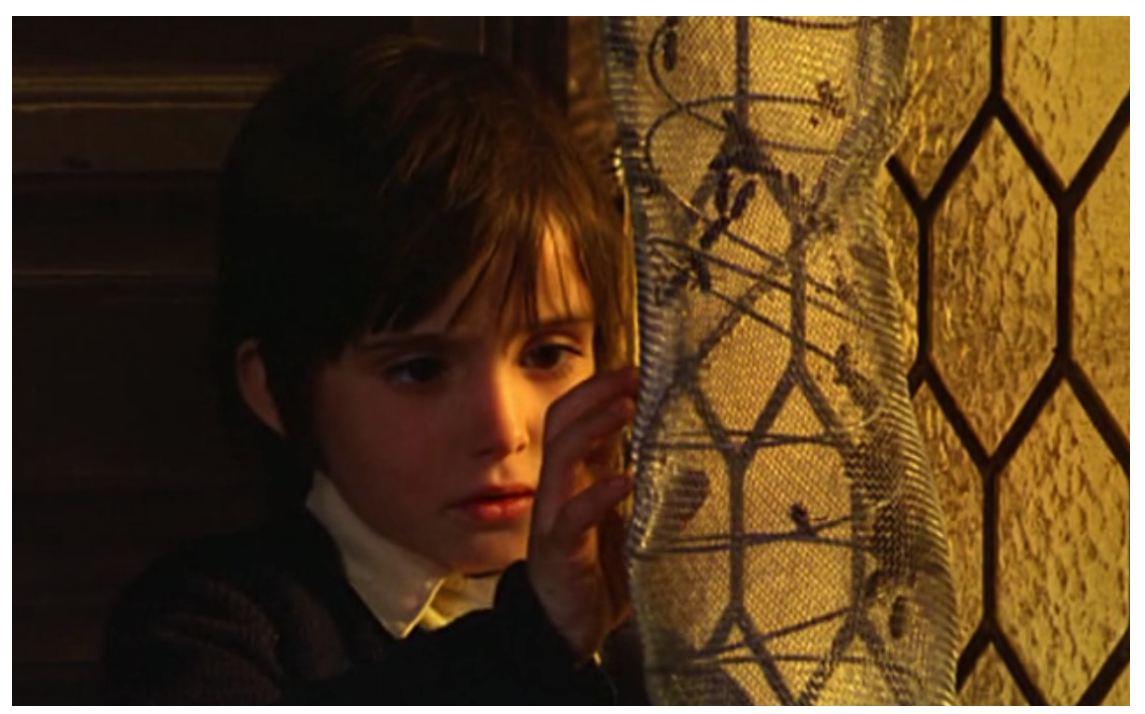

Figura 6: Imagem do filme El espíritu de la colmena. 
ano I número 1

temáticas

livres

Sua personagem principal, Ana, uma criança de seis anos, é absorvida pela força mitificadora do filme Frankenstein, exibido na comunidade em que vive. Confundindo realidade e fantasia, ao longo da narrativa, a personagem tem no mito da morte a revelação essencial do mundo ordenado pela colmeia. Os mecanismos de uma "narrativa embedada" já estão presentes em Frankenstein: “nesse romance, leitores percorrem seu caminho para dentro e para fora de uma sucessão de pelo menos seis diferentes narrativas, cada uma com narrador próprio, encasuladas como em caixas chinesas" (ABBOTT, 2008: 29). ${ }^{6}$

Esses mecanismos absor vem a personagem, que apenas consegue diferenciar a ficção da realidade, o simulacro da vivência do real, a partir da dissolução das dualidades bem versus mal, interior versus exterior, plasmadas pela colmeia, território do igual, do indistinto, do uniforme.

Narrativa dentro de narrativa, El espíruto de la colmena materializa a ideia de janelas no cinema, a partir das quais são narrados os acontecimentos. Incorpora uma concepção de história que transcende a linearidade espaçotemporal e pratica o descentramento narrativo, delegando vozes e exercitando novas formas de contar a alguém que algo aconteceu. São narrativas diegéticas que simulam a metáfora mimética da janela, que empregam os artifícios hipermediados com a finalidade de criar efeitos de opacidade e transparência que evidenciam o caráter extremamente opaco do discurso.

\subsection{Narrativas nas mídias digitais}

Já nas mídias digitais, esse caráter opaco fica evidente. As diversas formas interativas possibilitadas transbordam o que podemos chamar de narrativa linear ao promover a emergência de uma forma bastante peculiar

6. "In this novel, readers make their way in and then out of a succession of at least six different narratives, each with its own narrator, nested like Chinese Boxes." (Tradução da autora.) 
de narrativa. Suas características imersivas (espaciais e enciclopédicas) e interativas (participativas e procedimentais) (MURRAY, 2003) favorecem o desenvolvimento dos prazeres genuínos e intrínsecos à narrativa no ciberespaço, entre eles a imersão e a agência.

As janelas dispostas pelas mídias digitais compõem uma forma de contar histórias e relacionar trama e fábula que transcende os limites dos artifícios hipermediados no cinema. Se a narrativa é formada por um componente que permite a tradução pelos esquemas cognitivos em algo coerente cronologicamente - mesmo que de modo confuso e que não siga a ordem espaçotemporal dos acontecimentos -, a narrativa nas mídias digitais pode ainda ser chamada de narrativa? Aquilo que chamamos de narrativa digital é, na verdade, uma criação hipertextual que depende mais da exploração do potencial metafórico das janelas dispostas.

As "narrativas embedadas" tem um lugar especial nesse contexto: um video do YouTube, por exemplo, tocado dentro de um navegador (browser) qualquer, cria um efeito metafórico que conjuga tanto a perspectiva como narração mimética (em função do caráter hiperperspectivista) quanto a metalinguagem e a enunciação como mediadoras de uma diegese fundadora da narrativa, dando lugar a um jogo de molduras hipermediadas (como as caixas chinesas) e imediadas (imersivas), dependendo do nível de atividade do espectador.

O ciberespaço deve, assim, ser concebido como um mundo virtual global coerente, como virtualidade disponível, independente das configurações específicas que um usuário particular consegue extrair dele. De sua interface hipertextual emergem metáforas procedentes do mundo real, criando um sistema de comunicação eletrônica global que reúne humanos e computadores em uma relação simbiótica que cresce exponencialmente graças à comunicação interativa. O ciberespaço é o espaço que se abre quando o usuário conectase com a rede, por meio da simulação virtual do mundo físico de acordo com coordenadas perspectivistas ou não, em diferentes graus de imersão. 
ano I número 1

temáticas

livres

Novas formas de agenciamento, portanto. Novas formas de conceber o sujeito, não mais de acordo com os mecanismos de identificação e projeção idealizados pelo dispositivo do cinema e operados a partir das janelas miméticas. E a chave desses processos está justamente na hipermídia. Formada pelo hipertexto, por nós de informação e por uma estrutura multimídia, ela é marcada pela hibridização de linguagens e processos sígnicos.

A digitalização também permite (no entanto, não é condição única) a organização reticular dos fluxos informacionais em arquiteturas hipertextuais. Esse caráter não sequencial multidimensional dá suporte a infinitas opções de um leitor imersivo. O hipertexto quebra a linearidade em unidades ou módulos de informação. Nós e nexos associativos são a base da sua construção das molduras, que em geral consistem daquilo que cabe em uma tela. Ele é, claramente, formado por textos multimodais, em que se conjugam códigos fortes e fracos de forma a apontar a uma difícil fragmentação dos enunciados em unidades analisáveis.

Ao contrário dos textos audiovisuais cuja barreira analítica está na instabilidade semântica entre o plano da expressão e o plano do conteúdo, em função da multiplicidade de fontes de sentido, no hipertexto a unidade de significação confunde-se com a noção de hiperlink:

O link, elemento que o hipertexto acrescenta à escrita, preenche lacunas entre o texto - pedaços de texto - e, portanto, produz efeitos semelhantes à analogia, à metáfora e a outras formas de pensamento, outras figuras, que tomamos para definir poesia e pensamento poético. (LANDOW apud ABBOTT, 2008: 34)

Estudos teóricos admitem uma forma bastante particular de intermidialidade: a remediação, estratégia de representação de um meio em outro (BOLTER;

7. "The link, the element that hypertext adds to writing, bridges gaps between text - bits of text - and thereby produces effects similar to analogy, metaphor, and other forms of thought, other figures, that we take to define poetry and poetic thought." (Tradução da autora.) 
GRUSIN, 2000). Se a intermidialidade se constitui no estudo das relações entre um e outro meio, a remediação diz respeito a um tipo específico de relação, no qual a rivalidade e convivência são combinadas de modo a buscar reconhecimento cultural entre seus públicos.

Se a heterogeneidade dos textos audiovisuais já dificultava o estudo das figuras de linguagem e dos processos de significação, no hipertexto a intermidialidade eleva ainda mais esse grau de complexidade. A ênfase do discurso teórico da contemporaneidade nos processos de transposição e adaptação intersemiótica se dá não apenas em função das novas experiências midiáticas advindas desse fenômeno, mas pela complexificação de outros estatutos teóricos, como o conceito de gênero e mesmo de sujeito. Nesse sentido, as barreiras da intermidialidade transformam-se em dificuldades teóricas e analíticas. Nesse contexto, também, o termo “intermidialidade", dentro do discurso teórico da Comunicação, substitui e inclui os termos “adaptação" e "tradução intersemiótica”.

As relações dialógicas entre as diferentes mídias são evidenciadas no hipertexto, marcado pela coabitação de signos icônicos e plásticos, ou seja, signos cujos referentes possuem referente semelhante e aqueles cujo referente praticamente inexiste, respectivamente. Sendo o hipertexto uma rede de relações constante em que a dinamicidade dos enunciados está em função das possibilidades interativas, o sentido nos ambientes digitais provém não apenas do momento de recepção do processo comunicativo, mas do jogo entre autor e leitor. Falar em produção e recepção no hipertexto já é um contrassenso, dado o caráter de obra aberta (nos moldes de Umberto Eco) que o hipertexto adquire.

Esse jogo metafórico integra o percurso teórico e analítico a partir do qual o cinema e as mídias digitais - observados por meio dos exemplos listados nesse artigo - se construíram como manifestações estéticas e artísticas que jogam o espectador para dentro do amálgama do sentido na relação entre 
ano I número 1

\section{temáticas}

livres plano da expressão e plano do conteúdo. O efeito poético emerge desse potencial remediado (hipermediado e imediado) das mídias digitais, que já anunciava o cinema moderno.

As narrativas da cibercultura se formam, assim, por meio de composições e transposições que empregam estratégias de transparência e opacidade, com a finalidade de dar a ver as inter-relações de tramas e fábulas, construindo verdadeiros mundos de significação, emoldurados no cinema e nas mídias digitais. 


\section{Bibliografia}

ABBOTT, P. H. The Cambridge introduction to narrative. Cambridge; Nova York: Cambridge University Press, 2008.

AUMONT, J. A imagem. Campinas, SP: Papirus, 1993.

BOLTER, J. D.; GRUSIN, R. Remediation: understanding new media. Cambridge: The MIT Press, 2000.

BORDWELL, D. Narration in the fiction film. Madison: University of Wisconsin, 1985.

JOHNSON, S. Cultura da interface. Rio de Janeiro: Jorge Zahar, 2001.

MACEK, J. “Defining cyberculture”. 2005. Disponível em: http://macek.czechian.net/ defining_cyberculture.htm. Acessado em: 25 de junho de 2012.

MACHADO, A. O sujeito na tela: modos de enunciação no cinema e no ciberespaço. São Paulo: Paulus, 2007.

MURRAY, J. Hamlet no Holodeck: o futuro da narrativa no ciberespaço. São Paulo: Itaú Cultural; Unesp, 2003.

PURSER, R. E. "Cyberspace and its limits: hypermodern detours in the evolution of consciousness". Paper presented at the XXV International Jean Gebser Society Conference, October 21-24, 1999.Matteson, Ilinois: Governors State University.

RYAN, M.-L. Narrative across media: the languages of storytelling. Lincoln; Londres: University of Nebraska Press, 2004.

SERELLE, M. "Metatevê: a mediação como realidade apreensível”. Matrizes, vol. 2, n. 2, jun. 2009. Disponível em: www.matrizes.usp.br.

TURKLE, S. A vida no ecrã: a identidade na era da internet. Lisboa: Relógio D’Água, 1997. 


\section{Obras audiovisuais}

ano 1 número 1

temáticas

livres
ARCA RUSSA. Aleksandr Sokúrov. Rússia, Alemanha, 2002, filme, 96 mm.

EL ESPÍRITU DE LA COLMENA. Victor Erice. Espanha, 1973, filme, 97 mm. OBSERVANCE. Bill Viola. 2002, filme. 